Voix et Images

\title{
Les Autres Littératures d'expression française en Amérique du Nord
}

\section{Dean R. Louder}

Volume 13, numéro 2 (38), hiver 1988

Le propre du corps Roger Des Roches

URI : https://id.erudit.org/iderudit/200716ar

DOI : https://doi.org/10.7202/200716ar

Aller au sommaire du numéro

Éditeur(s)

Université du Québec à Montréal

ISSN

0318-9201 (imprimé)

1705-933X (numérique)

Découvrir la revue

Citer cet article

Louder, D. R. (1988). Les Autres Littératures d'expression française en Amérique du Nord. Voix et Images, 13(2), 334-336. https://doi.org/10.7202/200716ar d'utilisation que vous pouvez consulter en ligne.

https://apropos.erudit.org/fr/usagers/politique-dutilisation/ 


\title{
Les Autres Littératures d'expression française en Amérique du Nord 1
}

\author{
par Dean R. Louder, Université Laval
}

Un peuple sans littérature écrite est un peuple qui se meurt. Voilà le propos tenu par Annette Saint-Pierre, femme de lettres de Saint-Boniface, pour souligner à la page 74 de cet ouvrage fort intéressant que les francophones de l'Ouest veulent une place dans la littérature canadienne-française. Un tel propos semblerait caractériser tout autant les autres composantes de la francophonie nordaméricaine hors Québec dont certains représentants se sont réunis à Cornwall en mars 1984 pour discuter des autres littératures d'expression française en Amérique du Nord, celles du milieu anglophone majoritaire d'Amérique du Nord. Sur les treize textes du recueil, onze traitent d'écrits régionaux: trois sur l'Ontario, deux sur l'Ouest canadien, deux sur l'Acadie, deux sur la Louisiane, un sur la Nouvelle-Angleterre et un sur le Midwest américain. Le premier et le dernier des articles tentent de mettre en contexte l'ensemble des interventions.

En parlant de divorce et de réconciliation au sein de la grande famille canadienne-française, Eric Waddell réussit à brosser un tableau de cette Amérique française hétéroclite, géographiquement éclatée et politiquement démunie. Il évoque le rôle prépondérant, mais modeste, que devrait jouer le Québec comme foyer culturel, voire mère patrie, de la diaspora française en Amérique.

Utilisant le cadre conceptuel du psychiatre américain Thomas A. Harris (I'm OK/Y ou're OK: Practical Guide to Transactional Analysis), Pierre Paul Karch analyse des textes de quelques poètes franco-ontariens dans la perspective d'une évolution de cette poésie. On passe d'une thématique de l'oppression et de la discrimination ( $\mathbf{I}^{\prime} \mathrm{m}$ not $\mathrm{OK} / \mathrm{Y}$ ou're OK), si évidente dans l'œuvre de Patrice Desbiens, analysée ici par Robert Dickson (Autre, Ailleurs, Dépossédé) à un nouvel humanisme marqué par le respect et la fraternité (I'm OK/Y ou're OK). Cette nouvelle approche transparaît surtout dans certains des travaux récents de Jean-Marc Dalpé. Le troisième texte sur l'Ontario français, «la Belle Perdrix verte», renvoie surtout aux vingt volumes de contes traditionnels recueillis par Germain Lemieux et publiés sous le titre les Vieux m'ont conté.

S'intéressant à la littérature albertaine, Roger Motut insiste sur l'hétérogénéité de la francophonie de l'Ouest. En dépit de leur nombre prépondérant, les Canadiens français ont écrit relativement peu. Ce sont surtout les Français et les Suisses (Constantin-Weyer, Bugnet, Rouquette et Borel) qui racontent l'aventure et le romantisme de l'Ouest canadien. Malgré un titre qui se réfère à l'Alberta, Motut a peine à mentionner un auteur vraiment originaire de cette province mis à part Marguerite Primeau. Cela suffit-il à caractériser la littérature francoalbertaine? Annette Saint-Pierre souligne davantage les contributions métisse et canadienne-française. Elle insiste bien sûr sur la plus grande des auteures de 
l'Ouest, Gabrielle Roy, dont la majorité de la production littéraire révèle l'attachement à son sol, son histoire, sa vie et son temps.

Melvin Gallant note que le roman acadien est très récent. L'écriture acadienne ne s'affirme comme distincte, authentique et originale qu'en 1972 et cela surtout grâce à Antonine Maillet. Mais si les Acadiens doivent beaucoup à Maillet pour avoir mis en valeur et fait accepter l'écriture acadienne, les intellectuels lui reprochent d'avoir créé un genre contraignant, un style de roman résolument fixé dans l'histoire, le passé. Ce n'est qu'en 1983, avec la publication de l'Été aux puits secs de Germaine Comeau et de les Portes tournantes de Jacques Savoie, que le roman acadien s'éloigne des valeurs ancestrales, pour entrer de plain-pied dans le modernisme. Hans Runte, quant à lui, annonce quatre manières prometteuses de dire l'Acadie moderne. On retient surtout chez lui cette sévère critique à l'endroit de Maillet:

Je laisserai enfin de côté les écrivains folklorisants que semble souvent animer le seul souci d'épater le bourgeois québécois ou parisien. Ce ne sont ni le passéisme, ni le régionalisme, ni le folklorisme ou «cutisme» qui alimenteront une éventuelle poétique acadienne.

L'unique article en provenance de la Franco-Américanie est celui d'Armand Chartier qui suggère que la richesse de ce corpus littéraire méconnu et mal défini se trouve dans plus de 300 journaux de langue française publiés sur le territoire américain depuis deux siècles: un lien étroit et profond entre littérature et journalisme. L'une des meilleures en ce sens fut la chroniqueuse Yvonne Le Maître, une «déesse» de la plume. À son sujet, Chartier ne tarit pas d'éloges.

Selon Mathé Allain, le pays des Cajuns et des Créoles a toujours souffert d'être défini de l'extérieur. La renaissance littéraire des dix dernières années serait une tentative de redéfinition à partir de l'intérieur. L'un des artisans les plus importants de ce renouveau est Barry Ancelet. Il présente et commente ici de savoureux poèmes qui rappellent qu'en "Acadie tropicale», ce ne sont pas que les bons temps qui roulent. L'originalité de cette nouvelle écriture louisianaise se trouve dans son oralité. Sans elle, impossible de parier sur l'avenir.

D'autres l'ont fait en leur temps: Frank Barclay et Jules Leroux qui fondèrent respectivement au siècle dernier les journaux l'Estafette du Kansas et l'Étoile du Kansas. Leurs lecteurs disparurent! Bryant Freeman en fait état dans un court texte plutôt historique. Il rappelle aussi les recherches réalisées par son mentor Joseph-Médard Carrière qui a visité à peu près toutes les communautés françaises du Midwest au début des années trente. La «littérature» du Midwest est donc marquée de deux genres d'«écritures», l'oraliture et le journalisme. Des deux, c'est la première qui laissa davantage son empreinte.

Le mot de la fin est accordé à Robert Cornevin de l'Association des écrivains de langue française et délégué du gouvernement français au colloque. Celui-ci connaît fort peu la problématique de la francophonie nord-américaine, mais il fait 
état de la diversité de la francophonie mondiale.

Deux bibliographies partielles viennent compléter le tout, l'une sur la littérature récente de l'Ontario, de l'Acadie et de l'Ouest canadien et l'autre sur les écrits louisianais français de 1900 à nos jours. On regrette l'absence d'une bibliographie sur la littérature franco-américaine.

Un peuple sans littérature écrite est un peuple qui se meurt. Peut-être, mais ce peuple peut-il s'exprimer dans une langue qui n'est pas la sienne ou celle de ses ancêtres sans mourir? Armand Chartier parle d'une littérature francoaméricaine de langue anglaise et l'on retrouve également dans la première bibliographie quelques titres en anglais. Que faire de ces autres littératures qui ne sont pas d'expression française, mais d'inspiration francophone? Elles sont de plus en plus nombreuses, surtout dans le contexte franco-américain. Ne citons que les œuvres de Jack Kerouac (Dr. Sax, Visions of Gerard, Maggie Cassidy), d'Ernest Hébert (A Little More than Kin, Dogs of March, Whisper My Name) et de David Plante (The Foreigner, les romans Francœur - Family, Wood, Country). Que dire de ce roman de Russell Banks, Continental Drift, et comment le classer, lui qui décrit la rencontre brutale et très personnelle entre l'Amérique française (le Franco-Américain Bob Dubois qui fait le trafic de fuyards) et l'Amérique créole (la Haïtienne Vanise qui cherche désespérément à atteindre les côtes de la Floride)?

Un monde complexe que cette francophonie nord-américaine, mais un monde fort original et particulièrement pertinent à l'ère de l'émergence d'une communauté internationale qui s'appelle Francophonie. Il existe des défis à relever autant chez les littéraires que chez les politicologues et les politiciens. Les Autres Littératures d'expression française en Amérique du Nord offre plusieurs pistes à la réflexion.

1 Jules Tessier et Pierre-Louis Vaillancourt (sous la direction de), les Autres Littératures d'expression française en Amérique du Nord, Cahiers du CRCFF, $n^{\circ}$ 24, Ottawa, Editions de l'Université d'Ottawa, 1987, 164 p. 